\title{
Finite Element Analysis of Impact Loaded Polymer Composites Side Door Anti-intrusion Bar
}

\author{
Murat Yazici, İ.Kürşad Kandirmiş, İdris Karen, Harun Güçlü, Cemal Somyak
}

\begin{abstract}
Reducing the weight of vehicles is crucial for fuel economy correspondingly $\mathrm{CO}_{2}$ emissions. Therefore, Automobile manufacturers are constantly working on lightweight materials alternatively. Crashworthiness is another principal task for the car manufacturers. For this purpose, additional parts exist in the car body, such as frontal crash bumper beams, crash boxes, and side door antiintrusion bars. In the presented study, the side door anti-intrusion bar was selected to analyze with different composite materials to compare to existing steel models by using Finite Element Method (FEM). The same geometry but different thickness for Glass and Carbon fiber reinforced thermoset, and thermoplastic composites were applied in the FEM simulations.

Keyword: Side door impact, Anti-intrusion Bar, Fiber Reinforced Polymer Composites, Lightweight materials
\end{abstract}

\section{INTRODUCTION}

The fuel efficiency and gas emission regulations of the vehicles have become crucial in recent years. The price of fuel has rising day by day and emission of gasses from vehicle exhaust polluting World more and more [1].

Therefore, the automotive industry has paid close attention to reducing the weight of vehicles without ignoring crashworthiness of vehicle safety components. For this purpose, designers have faced to composite materials due to having the higher specific strength and higher specific stiffness than conventional

Murat Yazici

Uludag University Eng. Faculty, Automotive Eng. Dept.

Bursa/Turkey

I.Kürşad Kandirmiş

Amasya University, Technology Faculty, Automotive Eng.Dept Turkey

Idris Karen

Bursa Orhangazi University, Eng. Faculty, Mech. Eng. Dept.

Bursa/ Turkey

Harun Güçlü

Uludag University Eng. Faculty, Automotive Eng. Dept.

Bursa/Turkey

Cemal Somyak

Tofaș-FIAT
Selected material properties were obtained from the literature. Simulation results were compared to find highest bending rigidity and energy absorption capability of the anti-intrusion bar in the same boundary conditions and loading. Analyzed antiintrusion bar's CAD data and mesh structures were obtained by using CATIA and HyperMesh commercial software respectively. Abaqus dynamic/explicit FEM analysis were performed to obtain impact behavior of the anti-intrusion bars. The results showed that polymer composites had enough strength, rigidity and energy absorption capability to replace the existing steel model by reducing weight considerably.

For this purpose, designers have faced to composite materials due to having the higher specific strength and higher specific stiffness than conventional materials. Moreover, they also have high damping and impact characteristics. Consequently, as the price has fallen, composite materials are now widely used in automotive industry[2].

Thermoplastic composites (TPCs) have become more attractive for industry to product components as TPCs provide some advantages over Thermoset Composites (TSCs). TPCs are tough, can be formed or molded quickly through the application of heat and above all they can be recycled easily and produced with the little waste of materials. So these factors made manufacturers appeal strongly to work on TPCs[3].

The matrix in TPCs involve polypropylene (PP), polyethylene (PE), nylon or other inexpensive polymers. E-glass fiber is most frequently used reinforced material. With highest growth rate about $30 \%$ per year in plastic industry in recent years, Long Fiber Reinforced Thermoplastic composite's (LFRT) aspect ratio (1/d) of fibers is an order of magnitude greater than that of short fiber, often exceeding $1 / \mathrm{d}$ of 2000 and thus take full advantages of the strength of reinforcing fibers [4]. 
With respect to vehicle safety regulations, like Federal Motor Vehicle Safety Standards (FMVSS) and Euro NCAP, vehicle components that involved active or inactive safety systems, have to be endurable in some crash situations. For instance, each door can resist simulated forces that applied by impactor. For this reason, the designers always use the anti-intrusion bar to compensate the requirement of side door strength. The major function of side door anti-intrusion bar is to provide maximum safety to the passenger. Side door anti-intrusion bar is placed into the car door body and designed to lessen the penetration to passenger compartment in case of side crash situation [1].

In the presented study the side door antiintrusion bar, currently used in commercial vehicles, was selected to analyze with different composite materials to compare to existing steel models by using Finite Element Method (FEM). The same geometry but different thickness for Glass and Carbon fiber reinforced thermoset and glass fiber reinforced thermoplastic composite were applied in the FEM simulations. Selected material properties were obtained from the literature. Simulations were made accordance to FMVSS 214 [5] [6] procedures to find highest bending rigidity and energy absorption capability of the anti-intrusion bar in the same boundary conditions and loading. Abaqus dynamic/explicit FEM analysis were performed to obtain impact behavior of the anti-intrusion bars.

\section{MATERIALS AND METHODS}

\section{A. Finite Element Model}

In order to compare impact behavior of different materials, current anti-intrusion bar CAD data's has taken from Tofaş-FIAT. The bar has $2 \mathrm{~mm}$ thickness, $1036 \mathrm{~mm}$ length and $115 \mathrm{~mm}$ width. Fig.1 shows CAD model, created by using CATIA Software. The model meshed for finite element analysis (FEA) using HyperMesh Software. Fig. 2 shows meshed model, consist of 21243 nodes and 20513 linear quadrilateral elements.

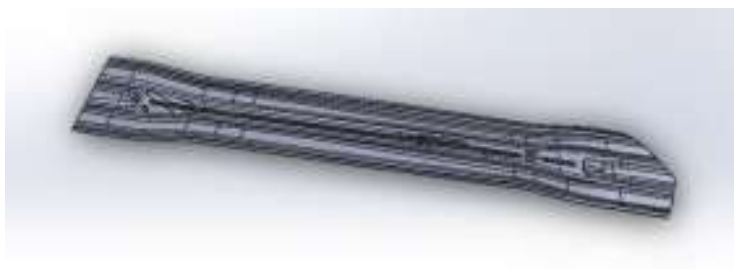

Fig.1 CAD model of Anti-intrusion bar

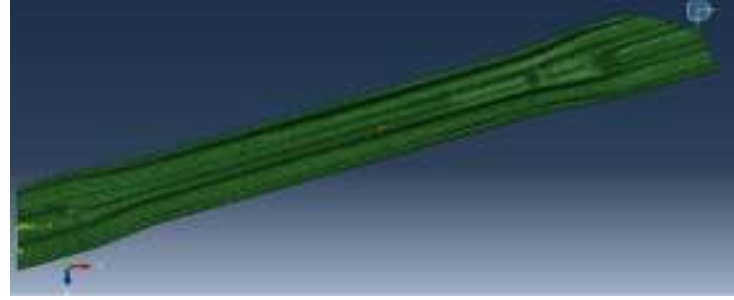

Fig.2 Meshed Model

The boundary conditions for side door anti-intrusion bar have a major importance to get real like impact analysis results. The Orphan Meshed model is imported to Abaqus/Explicit software for FEA. Boundary conditions for fixing type and fixing points are identified as like real conditions. As a first analysis, the bar is examined with different materials to see how bar behaves under instantaneously distributed load. The load is applied surfaces which face any impact load firstly. For two analysis bar is fixed as encastre from door connection points and distributed load is applied directly to the bar. Fig. 3 shows load and fixings. The load has a characteristic as time depended on amplitude (Table 4.).

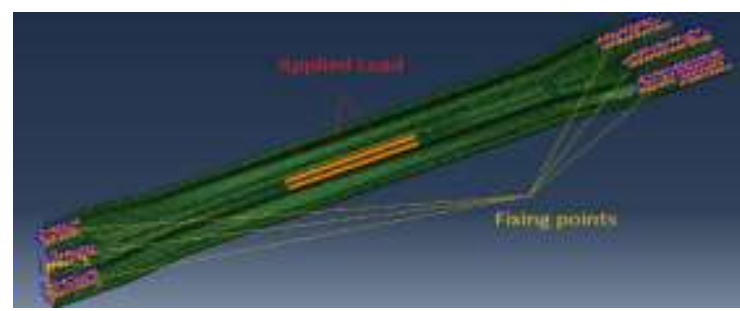

Fig.3 Load and Boundary Conditions

TABLE 1. TIME DEPENDED ON LOAD AMPLITUDE

\begin{tabular}{cc}
\hline Time/Frequency & Amplitude \\
\hline 0.001 & 1 \\
0.002 & 1.50 \\
0.003 & 1.75 \\
0.004 & 2 \\
0.005 & 2.5 \\
0.006 & 3 \\
0.007 & 3.5 \\
0.008 & 4 \\
0.009 & 4.5 \\
0.01 & 5 \\
\hline
\end{tabular}

The structure of the bar is selected as a homogeneous shell. For steel and aluminum bar thickness is $2 \mathrm{~mm}$ but for two types of composite materials structure is built as 8 layers and each layer thickness is $0.25 \mathrm{~mm}$. Lay-ups vary as $0 / 90$ or $+45 /-45$ for each composite type.

Second analysis based on the FMVS Standard. The conditions for the impact simulations like size and velocity of the impactor is taken from FMVS Standards. Fig.4 shows standard impact test of FMVSS [5]. 


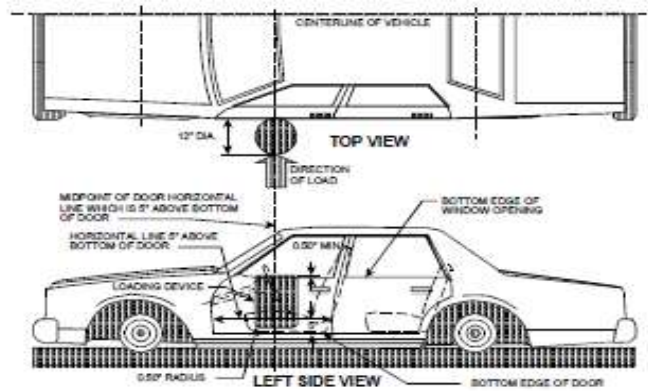

Fig.4 FMVSS Front Door Test[5]

Impact barrier's dia. is $305 \mathrm{~mm}$ and has a velocity of 35 $\mathrm{km} / \mathrm{h}$. Anti-intrusion bar is fixed from junction points as encastre. Crash type as side impact, obstruction as a rigid barrier and simulation time is $10 \mathrm{~ms}$. Fig. 5 shows analysis model.

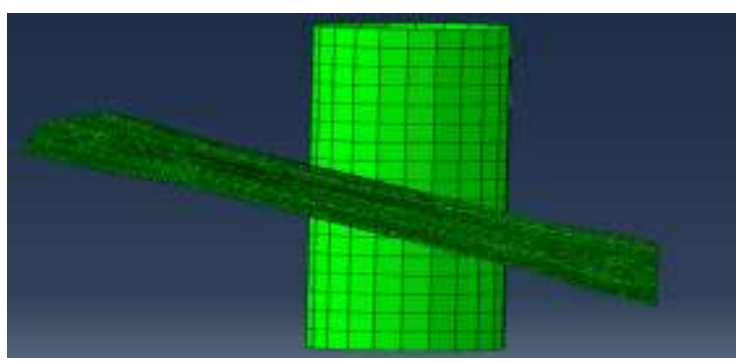

Fig.5 Barrier crush model

\section{B. Damage Model of Fiber - Reinforced Composite}

Abaqus uses Hashin Damage Criteria that assumes three dimensional failure criterion using average stresses or strains [7] for fiber reinforced composite materials. FEA software considers four essential conditions:

- $\quad$ The damage in the material is anisotropic.

- Four different failure modes are taken into account: fiber tension, fiber compression, matrix tension and matrix compression.

- $\quad$ The behavior of the undamaged material is linearly elastic.

- $\quad$ The model must be used with elements of a plane stress formulation (plane stress, shell, continuum shell and membrane elements).

Hashin Failure Criterion failure modes are formulated below [8];

- Fiber Tension Failure formulation :

$$
\mathrm{f}_{1}=\left(\frac{\sigma_{11}}{X^{t}}\right)^{2}+\left(\alpha \frac{\sigma_{12}}{\tau_{12 u}}\right)^{2} \quad \text { where } 0 \leq \alpha \leq 1
$$

- Fiber Compression Failure formulation:

$$
\mathrm{f}_{2}=\left(\frac{\sigma_{11}}{X^{C}}\right)^{2}
$$

- Matrix Tension Failure formulation :

$$
\mathrm{f}_{3}=\left(\frac{\sigma_{22}}{Y^{t}}\right)^{2}+\left(\frac{\sigma_{12}}{\tau_{12 u}}\right)^{2}
$$

- Matrix Compression Failure formulation :

$$
\mathrm{f}_{4}=\left(\frac{\sigma_{22}}{2 \tau_{13 u}}\right)^{2}+\left[\left(\frac{Y^{C}}{2 \tau_{13 u}}\right)^{2}-1\right] \frac{\sigma_{22}}{Y^{C}}+\left(\frac{\sigma_{12}}{\tau_{12 u}}\right)^{2}
$$

\section{Side Door Anti-Intrusion Bar Materials}

FMVS Standard Number 214 identify the minimum strength required for the side door of a car. The side doors have to endure an initial crush resistance of at least $10008.5 \mathrm{~N}$ after $152.4 \mathrm{~mm}$ of displacements and average crush resistance of at least $15568.8 \mathrm{~N}$ without seats installed or $19460.96 \mathrm{~N}$ with seats installed after 304.8 $\mathrm{mm}$ displacements, and also a peak crush resistance of 2 times the weight of the vehicle or $31137.54 \mathrm{~N}$ whichever is less (without seats installed) or 3.5 times the weight of the vehicle or $53378.64 \mathrm{~N}$ whichever is less (with seat installed) after $457.2 \mathrm{~mm}$ of displacements [5].

The leading factors to choose door materials are load path and a maximum resisting load. Load carrying and absorption capacity and intrusion of the side door structure depends on mechanical properties, size, shape and thickness of components. The different combination of these factors can change the behavior of structure incredibly [9].

The side door anti-intrusion bar must have the ability of energy absorption as much as possible without breaking off. Steel is the most common used material for antiintrusion bar, but steel causes increase the total weight of the vehicle undesirably. As a result of studied on lighter materials like composite in the industry, with exact fiber orientation and stacking sequence of the cross-ply laminate, composites have higher energy absorption capacity than steel besides reducing the weight.

Commonly used steel bar is compared with aluminum, TSC (Glass Fiber Reinforced Epoxy Resin) and TPC (Glass Fiber Reinforced PP Resin). A mild steel mechanical properties are given as; E $=206 \mathrm{GPa}$, Density $(\rho)=7830 \mathrm{~kg} / \mathrm{m}^{3}, v=0.3[10]$

Mechanical properties of aluminum is given below as; $\mathrm{E}=70 \mathrm{GPa}$, Density $(\rho)=2780 \mathrm{~kg} / \mathrm{m}^{3}, v=0.33$ [11].

To identify the plastic behavior of steel and aluminum, True stress - Plastic strain data are given in Table 2. for steel [10] and Table 3. for aluminum;

TABle 2. True Stress - Plastic Strain Data For Steel

\begin{tabular}{cllllll}
\hline$\sigma(\mathrm{MPa})$ & 304.6 & 344 & 386 & 425 & 450 & 470 \\
$\varepsilon_{\mathrm{p}}$ & 0 & 0.02 & 0.05 & 0.1 & 0.14 & 0.19
\end{tabular}

TABLE 3. TRUE STRESS - Plastic STRAin DATA FOR THE ALUMINUM

\begin{tabular}{|c|c|c|c|c|c|c|c|c|}
\hline$\sigma(\mathrm{Mpa})$ & 80 & 115 & 139 & 150 & 158 & 167 & 171 & 173 \\
\hline$\varepsilon$ & 0 & 0.024 & 0.049 & 0.079 & 0.099 & 0.124 & 0.149 & 0.174 \\
\hline
\end{tabular}

There must be a damage criteria for composite materials in an explicit analysis. Abaqus/Explicit has the option to describe Hashin Damage criteria in itself to identify damage behavior of composite. Thermoset Composite material is unidirectional pultruded E-Glass Fiber/Epoxy 
matrix, and Thermo Plastic Composite material is E-Glass Fiber / Polypropylene (PP), matrix.

Table 4. shows mechanical properties and damage properties of unidirectional pultruded E-Glass/Epoxy [10].

TABle 4. Mechanical and DAMAge properties of EGLASS/EPOXY COMPOSITE

\begin{tabular}{cc}
\hline$\rho\left(\mathrm{kg} / \mathrm{m}^{3}\right)$ & 1850 \\
$\mathrm{E}_{11}(\mathrm{GPa})$ & 31,2 \\
$\mathrm{E}_{22}(\mathrm{GPa})$ & 9,36 \\
$\mathrm{G}_{12}(\mathrm{GPa})$ & 5 \\
$\mathrm{G}_{13}(\mathrm{GPa})$ & 5,5 \\
$\mathrm{G}_{23}(\mathrm{GPa})$ & 5,5 \\
$\mathrm{v}_{21}(\mathrm{Nu} 12)$ & 0,29 \\
$\mathrm{Xt}(\mathrm{Mpa})$ & 483 \\
$\mathrm{Xc}(\mathrm{Mpa})$ & 409 \\
$\mathrm{Yt}(\mathrm{Mpa})$ & 34,9 \\
$\mathrm{Yc}(\mathrm{Mpa})$ & 92,2 \\
$\mathrm{Sc}(\mathrm{Mpa})$ & 73,3 \\
\hline
\end{tabular}

TABle 5. Mechanical AND DAMAge PROPERTiEs of EGLASS/PP THERMOPLASTIC COMPOSITE

\begin{tabular}{cc}
\hline$\rho\left(\mathrm{kg} / \mathrm{m}^{3}\right)$ & 1500 \\
$\mathrm{E}_{11}(\mathrm{GPa})$ & 13,79 \\
$\mathrm{E}_{22}(\mathrm{GPa})$ & 12,97 \\
$\mathrm{G}_{12}(\mathrm{GPa})$ & 1,72 \\
$\mathrm{G}_{13}(\mathrm{GPa})$ & 1,79 \\
$\mathrm{G}_{23}(\mathrm{GPa})$ & 1,66 \\
$\mathrm{v}_{21}(\mathrm{Nu} 12)$ & 0,10 \\
$\mathrm{Xt}(\mathrm{Mpa})$ & 287,6 \\
$\mathrm{Xc}(\mathrm{Mpa})$ & 154,5 \\
$\mathrm{Yt}(\mathrm{Mpa})$ & 265,9 \\
$\mathrm{Yc}(\mathrm{Mpa})$ & 151,1 \\
$\tau_{12 \mathrm{u}}$ & 18,80 \\
$\tau_{13 \mathrm{u}}$ & 13,70 \\
$\tau_{23 \mathrm{u}}$ & 12,10 \\
\hline
\end{tabular}

Mechanical properties and damage properties of EGlass/PP Thermoplastic composite are shown in Table 5 [11].

\section{RESULTS}

\section{A. Displacement Results}

Fig.6 shows comparative results of displacement for all materials and orientations during analysis.

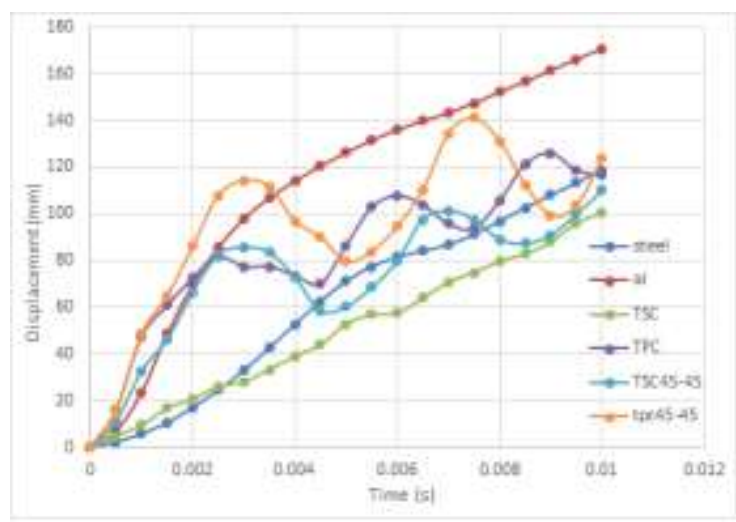

Fig.6 Displacement results

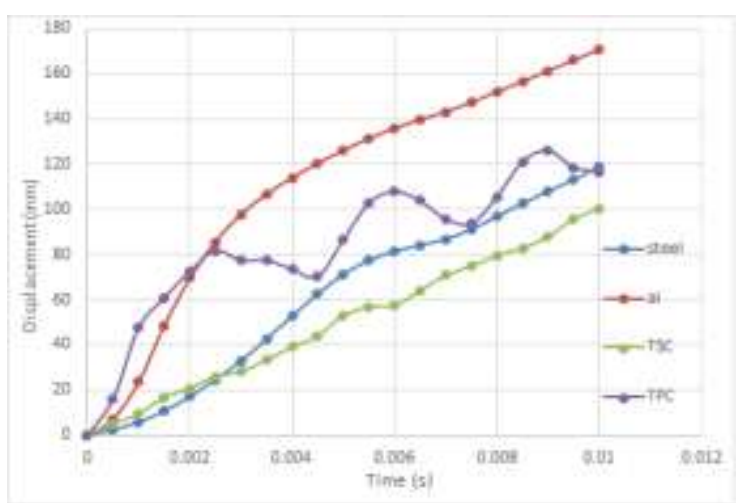

Fig.7 Displacement results for Steel, Al, TSC, TPC

Fig.7 shows comparative results of displacements for steel, aluminum, TSC and TPC materials. To compare steel and TPC, Fig. 8 clearly shows only steel and TPC's results of displacement.

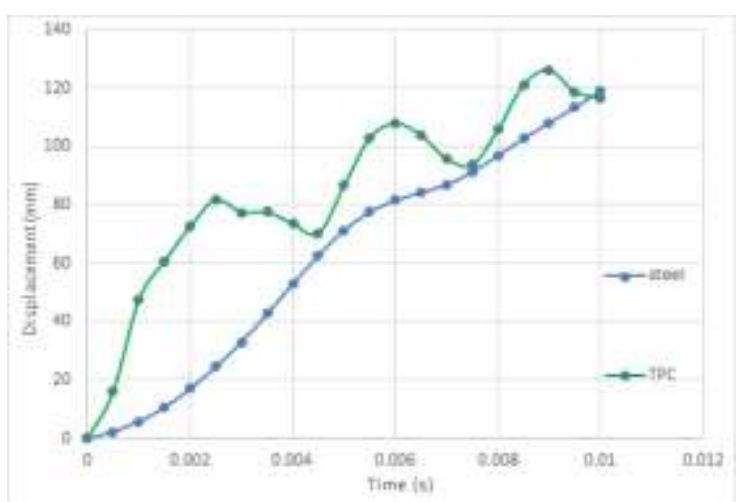

Fig.8 Displacement results for Steel and TPC

\section{B. Reaction Forces Results}

Fig.9 shows comparative results of Reaction forces for all materials and orientations during analysis. 
Proc. of the Fourth Intl. Conf. Advances in Civil, Structural and Mechanical Engineering- CSM 2016 Copyright (C) Institute of Research Engineers and Doctors, USA .All rights reserved.

ISBN: 978-1-63248-093-4 doi: 10.15224/ 978-1-63248-093-4-76

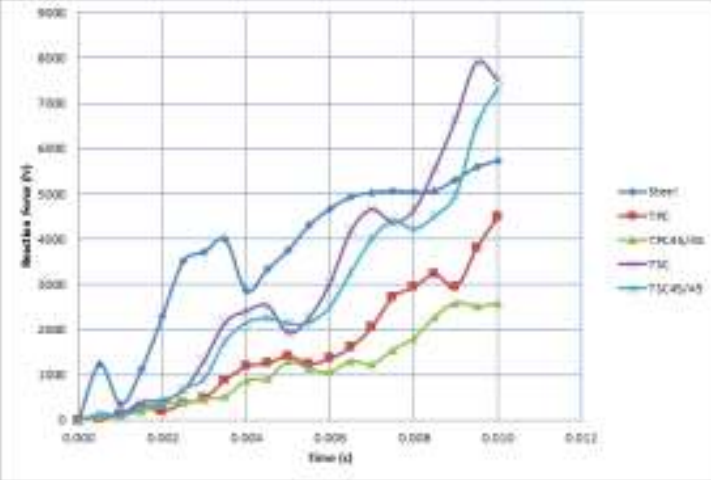

Fig.9 Reaction forces results

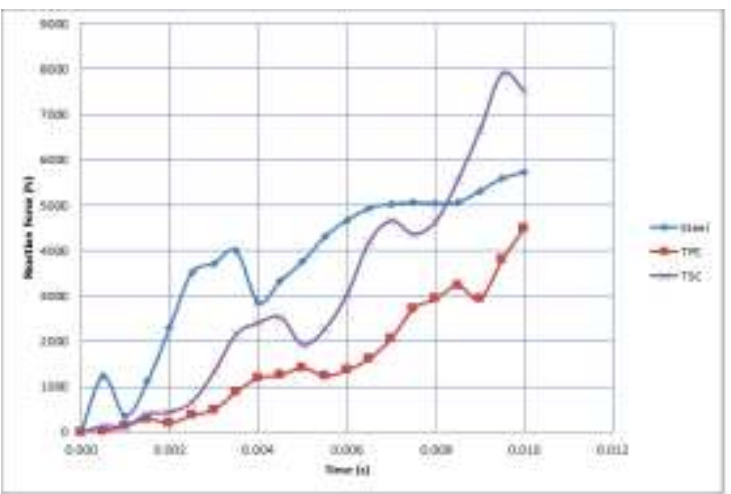

Fig.10 Reaction forces results for Steel, TSC and TPC

Fig.10 shows comparative results of Reaction Forces for steel, TSC and TPC materials. Fig.11 shows only steel and TPC results to compare clearly.

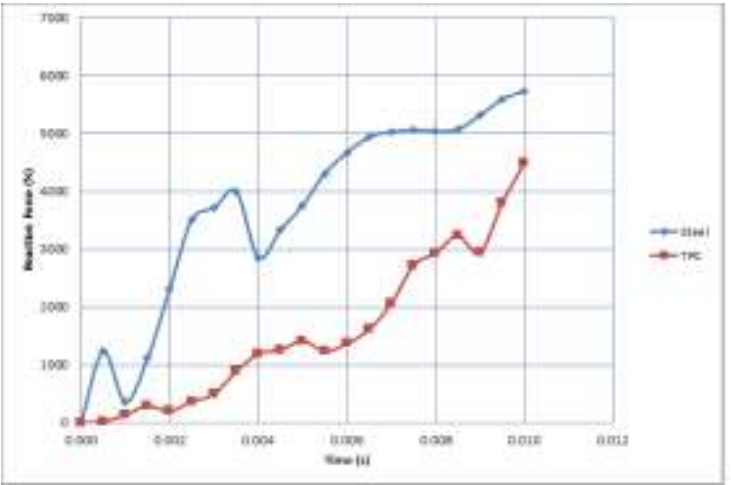

Fig.11 Reaction Forces results for steel and TPC

\section{Overall Results}

Table 6. shows overall comparative results including weight comparison.

TABLE 6. COMPARATIVE OVERALL RESULTS

\begin{tabular}{|c|c|c|c|c|}
\hline Material & $\begin{array}{c}\text { Max. } \\
\text { Displaceme } \\
\text { nt. (mm) }\end{array}$ & $\begin{array}{c}\text { Max. } \\
\text { Reaction } \\
\text { Force (N) }\end{array}$ & $\begin{array}{c}\text { Weight } \\
(\mathrm{g})\end{array}$ & $\begin{array}{c}\text { Weight } \\
\text { Reduction } \\
(\%)\end{array}$ \\
\hline Steel & 118.9 & 6098 & 1607 & 0 \\
\hline $\mathrm{Al}$ & 170.7 & 2712 & 571 & 64.5 \\
\hline $\begin{array}{c}\text { TSC } \\
(0 / 90)^{\circ}\end{array}$ & 102.2 & 10570 & 379.7 & 76.4 \\
\hline
\end{tabular}

\begin{tabular}{|c|c|c|c|c|}
\hline $\begin{array}{c}\text { TSC (45/- } \\
45)^{\circ}\end{array}$ & 108.6 & 9306 & 379.7 & 76.4 \\
\hline $\begin{array}{c}\text { TPC } \\
(0 / 90)^{\circ}\end{array}$ & 116.6 & 8999 & 307.9 & 80.7 \\
\hline $\begin{array}{c}\text { TPC }(45 /- \\
45)^{\circ}\end{array}$ & 123.5 & 5519 & 307.9 & 80.7 \\
\hline
\end{tabular}

\section{CONCLUSIONS}

In this study, a series of Finite Element Simulations were performed to compare impact behaviors of the anti-intrusion bar under the various materials and composite layers orientation options. The obtained conclusions were given below:

1) Aluminum anti-intrusion bar shows the best energy absorption capability.

2) $[45 /-45]_{4}$ laminated panels showed high impact behavior. This behavior comes from the internal fiber rotation flexibility. In the point of the weight reduction view, the laminated composite materials under $[45 /-45]_{4}$ orientation has the best performance between the studied materials.

3) Thermoplastic matrix materials showed better energy absorption properties than the thermoset matrix materials. The principal mechanism is the plastic deformability of the thermoplastic matrix material for this difference.

4) $[0 / 90]_{4}$ laminated composites showed less energy absorption properties than the $[45 /-45]_{4}$ composite laminates since they behave more rigid and brittle.

5) $[0 / 90]_{4}$ oriented laminated composite Thermoset matrix materials showed more brittle and rigid behavior. For that reason, they show the worst impact behavior between the simulated materials.

\section{ACKNOWLEDGEMENT}

The authors acknowledge the financial support of this study provided by TUBITAK-TEYDEB and TOFASFIAT Turkey, under Project Number: Tubitak-Teydeb $1505 / 5140018$.

\section{REFERENCES}

[1] Divakara H Basavaraju, "Design and Analysis Of A Composite Beam For Side Impact Protection Of A Sedan", Mysore University, India, 1998.

[2] Seong Sik Cheon, Dai Gil Lee and Kwang Seop Jeong, "Composite Side-Door Impact Beams For Passenger Cars”, Composite Structure Vol.38 No.1-4 pp. 229-239, 1997.

[3] Martin J Wilson, "Finite Element Analysis Of Glass Fibre Reinforced Thermoplastic Composites For Structural Automotive Components" Ph.D. Thesis, University of Nottingham, 2003.

[4] S Jeyanthi and J Janci Rani, "High Velocity Impact Analysis Of The Thermoplastic Bumpers in Automobiles", Journal of Scientific and Industrial Research Vol.73, January 2014, pp. 66-68.

[5] U.S. Department Of Transportation National Highway Traffic Safety Administration, Laboratory Test Procedure For FMVSS 214S (Static) Side Impact Protection, TP-214S-05, April $15,1992$.

[6] U.S. Department Of Transportation National Highway Traffic Safety Administration, Laboratory Test Procedure For 
The New Car Assessment Program Side Impact Moving Deformable Barrier Test,(FMVSS 214) Rev. 09/19/2012.

[7] Hashin Z., "Failure Criteria for Unidirectional Fiber Composites", Journal of Applied Mechanics, Vol.47, 1980, pp. 329-334

[8] Hashin Z., Rotem A., "A Fatigue Failure Criterion for Fiber- Reinforced Materials", Journal of Composite Materials, 7 (1993), pp. 448-464

[9] Farely,G.L., "Energy Absorption Of Composite Materials", Journal of Composite Materials, Vol.17, pp. 267-279, 1983.

[10] Giovanni Belingardi, Alem Tekalign Beyene, Ermias Gebrekidan Koricho, "Geometrical Optimization Of Bumper Beam Profile Made Of Pultruded Composite By Numerical Simulation", Composite Structures 102 (2013) 217-225.

[11] Saint-Gobain Vetrotex, "Data Base For 2-D Woven Fabrics -DCC1", France, 1998 